RAE-IC, Revista de la Asociación Española de Investigación de la Comunicación vol. 8, núm. 16 (2021), 72-97 ISSN 2341-2690

Recibido el 29 de junio de 2021

DOI: https://doi.org/10.24137/raeic.8.16.5 Aceptado el 23 de septiembre de 2021

\title{
La prensa musical española de los 80 como perpetuadora del androcentrismo
}

Spanish musical press in the 80's: perpetrator of androcentrism

Bronsoms, Angels

Universitat Autònoma de Barcelona (UAB)

angelsb@grn.es

Franquet, Rosa

Universitat Autònoma de Barcelona (UAB)

rosa.franquet@uab.cat

Forma de citar este artículo:

Bronsoms, A. y Franquet, R. (2021). La prensa musical española de los 80 como perpetuadora del androcentrismo. RAE-IC, Revista de la Asociación Española de Investigación de la Comunicación, 8(16), 72-97.

https://doi.org/10.24137/raeic.8.16.5

\section{Resumen:}

La presente investigación se inscribe en la tradición de los estudios de género y examina, mediante un análisis cuantitativo y cualitativo, una de las principales revistas musicales de España, como fue Vibraciones. El objetivo principal es conocer el tratamiento informativo otorgado a la mujer en la prensa musical, mediante un análisis de contenido 
que nos permita descubrir cómo se transmiten los roles y estereotipos y de qué manera se configuran las identidades sexuales en la música de la década de los ochenta del siglo pasado. Una fecha clave con cambios sociales, políticos y económicos que propicia el contexto adecuado para llevar a cabo un análisis de cómo la prensa musical ha ido incurriendo en una discriminación de género hacia las artistas. Los resultados muestran una cifra ínfima de contenidos e imágenes protagonizados por mujeres, abundando los estereotipos físicos compatibles con una cosificación y revelando que el lenguaje de los medios es un arma de control que puede utilizarse para ejecutar opresión, impregnando la obra de las mujeres de una misoginia que trasciende fronteras culturales, geográficas y estéticas.

Palabras clave: género, estereotipo, prensa musical, misoginia, rock.

\section{Abstract:}

The research that concerns us, inscribed in the tradition of gender studies, analyzes, through a quantitative and qualitative analysis, one of the more popular music magazines in Spain such as Vibraciones. The main objective is to identify the informational treatment given to women in the music press, through a content analysis that allows us to discover how roles and stereotypes are transmitted, and how sexual identities are configured in the music of the decade of the eighties of the last century. A key date with social, political and economic changes that provides the context from which to analyze the treatment given to artists in the music press. The results of the analysis unveiled a negligible number of content featuring women, and when they appeared -in the text or images-, was abounding physical stereotypes compatible with a sexual objectification. The findings revealed that the language of the media is used as a control weapon that can be used to execute oppression, permeating the work of women with a misogyny that transcends cultural, geographical and aesthetic boundaries.

Keywords: gender, stereotype, music press, misogyny, rock. 


\section{INTRODUCCIÓN}

La industria musical del siglo XX ha forjado ídolos e iconos mediáticos que han influenciado a las sucesivas generaciones de jóvenes $y$ ha contribuido a crear subculturas que comparten:

Una ideología, como forma de entender la sociedad y sus conflictos, dando base a su existencia y como filosofía de vida: una posición frente a la diferencia sexual, económica o étnica, qué se piensa de las autoridades, qué valor le dan a la salud, la participación sociopolítica, la violencia, las relaciones sexuales, etc. (Rubio y San Martín, 2012, p. 201).

En el despertar del tardofranquismo, la música fue un elemento identificador de gran importancia en el diseño de unas vidas alternativas y un proyecto cultural rupturista. La música solidifica y fomenta unas señas de identidad que por su naturaleza contestaria se opone a los sistemas políticos y sociales dominantes en momentos históricos.

En el periodo de estudio -1975-1985- el crítico de rock es auspiciado como gatekeeper que aprovecha los privilegios del patriarcado. En el análisis cuantitativo y cualitativo examinaremos cómo se fundamenta su participación y cómo se llevó a cabo la exclusión de género. Su evaluación de la diferencia de ser mujer se plasma mediante el uso de estereotipos sexistas, perspectiva que quedará probada en el análisis de portadas y titulares y de textos e imágenes de la revista Vibraciones. La segmentación por estereotipo de texto alcanza los 94 ejemplos reflejando cómo las prácticas periodísticas y la manipulación de imágenes, así como el uso de metáforas y axiomas enfatizan sus atributos físicos. Unas prácticas que cosifican a la mujer artista y le aplican unos prejuicios sancionadores que ahondan en su vida privada o pública presentándola como una mujer vicaria.

La elección de variables de análisis de fotografías ha resultado ser válida asimismo para justificar las hipótesis sobre cómo la prensa musical, altamente masculinizada, implementa su visión patriarcal e invisibiliza la obra de la mujer en la música.

Los medios de comunicación y, en concreto la revista musical Vibraciones, contribuyeron a generar y propagar estos mitos y darles consistencia. Conocer los 
valores culturales asociados a las informaciones de estas publicaciones y desgranar los sesgos y estereotipos relativos al género inspiran esta investigación.

\section{MARCO TEÓRICO}

La teoría feminista nos proporciona la categoría analítica del género, como punto de partida, para demostrar la misoginia de la prensa musical permitiéndonos trazar una línea de demarcación entre las diferencias sexuales biológicas y la forma en que estas se utilizan para informar sobre competencias y conductas y que luego se asignan como masculinas o femeninas (Pilcher y Whelehan, 2017).

Butler (2002) sugiere que la materialización del sexo es una construcción social, histórica y cultural y que un género performativo (Butler, 1990) se produce de forma discursiva, se aprende y normaliza por repetición.

Cusick (1994) propone que leamos el cuerpo como una metáfora del sistema de relaciones de poder entre cuerpos. Cada individuo es diferente y cada persona tiene y vive una experiencia diferente a la de otra. Por tanto, cada persona utilizará metáforas distintas para expresar su visión del mundo y construir su pensamiento.

El cuerpo no es un medio pasivo, no podemos acceder a la materia del cuerpo sino a través de la corporalidad de los discursos, prácticas y normas. Si las actuaciones musicales se pueden describir como representaciones de poder individuales y sociales, podríamos descubrir el género implícito y explícito asociado a ciertos actos musicalmente interpretativos, y aprender sobre cómo la música enseña o -posiblemente lo más importante- enseña el género. En el caso de las artistas, significa que deben ejercer una representación de normas creadas socialmente que se esperan de su género y que son asimiladas por la audiencia.

En la escucha de una música nos transportamos a unas narrativas culturales concretas. McClary (1994), presenta la música como un medio que participa en la formación social al influir en las formas en que percibimos nuestros sentimientos, nuestros cuerpos, nuestros deseos, nuestras propias subjetividades. Propone, al igual que Lauretis (1989), que la música es la más importante entre las tecnologías culturales del cuerpo 
I want to propose that music is foremost among cultural "technologies of the body", that is the site where we learn how to experience socially mediated patterns of kinetic energy, being in time, emotions, desire, pleasure, and much more (McClary, 1994, p. 445).

Bengoechea (2015) se interesa por el análisis del discurso y del lenguaje como ejes de las asimetrías de género: "el lenguaje como punto de articulación del vínculo entre representación, subjetividad e ideología" (2015, p. 12). Señala tres ejes de investigación cruciales para el estudio de la lengua y el género: "qué se dice de las mujeres, cómo se crean los discursos responsables del sistema de género y cómo hablan mujeres y hombres" (2015, p. 14).

En esta investigación, uno de los ejes de nuestro análisis son las coordenadas apuntadas por Bengoechea (2015) sobre los estudios lingüísticos. Los mismos promueven la disección de la lengua como sistema que se encarga de situar a las mujeres en el sitio que la jerarquía del género les asigna: género gramatical, ciertas construcciones léxicas y vocabularios que trivializan y degradan sus logros, construcciones verbales asimétricas con las que son nombradas invisibilizándolas y otorgándoles un papel secundario.

La tradición teórica de Mills (1995) sobre feminismos estilísticos es recogida por Montoro (2014) y Bengoechea (2015) que secundan este acervo para explicar cómo se materializan lingüísticamente los temas de género. En dichos estudios se valora el rol del lenguaje en crear, sostener y perpetuar las relaciones desiguales de género discriminando a las mujeres, a las personas gay, lesbianas o transgender.

La crítica de la concepción androcéntrica de la humanidad tiene como uno de sus fines contribuir a la construcción subjetiva y social de una nueva configuración a partir de la resignificación de la historia, la sociedad, la cultura y la política desde las mujeres y con las mujeres. Esta perspectiva reconoce la diversidad de géneros y la existencia de las mujeres y los hombres, como un principio esencial en la construcción de una humanidad diversa y democrática. La mirada a través de la perspectiva de género nombra de otras maneras las cosas conocidas, hace evidentes hechos ocultos y les otorga otros significados (Lagarde, 1996, p. 13).

\subsection{CONTEXTO SOCIAL Y POLÍTICO DE LA REVISTA VIBRACIONES}

RAE-IC, Revista de la Asociación Española de Investigación de la Comunicación vol. 8, núm. 16 (2021), 72-97 
La transición (1975-1986) fue una etapa política convulsa que favoreció una cultura underground muy distinta a las etapas anteriores y con influencias diversas que "pasaban por la contracultura norteamericana, el situacionismo, el rock, el punk, el libertarismo o los nuevos movimientos sociales" (Del Val, 2011, p. 75).

En la caracterización social de los jóvenes, seres culturales que no pueden desprenderse de sus experiencias en la vida cotidiana, las tribus urbanas son la metáfora del cambio. Feixa y Porzio (2004) definen las culturas juveniles como "un conjunto de estilos "espectaculares" que en España se difundieron sobre todo durante la etapa de transición democrática, siendo bautizados con el nombre de "tribus urbanas" (2004, p. 9).

Las tribus, primero corporeizadas por los hippies, y después por los estilos más variados: rockeros, mods, punks, heavies, skinheads, siniestros, tomaron forma en la vida pública de las ciudades impregnando unos terrenos de influencia mediáticas y musicales que tuvieron representación desigual en los medios de comunicación del momento.

La densidad de estas prácticas, de la que da cuenta su presencia en el archivo cultural, permiten comprender la Transición como el lugar de una profunda "revolución cultural" más allá de las formas políticas institucionales (las del régimen de 1978) y de sus modos culturales (los de la llamada Movida ochentera) (Labrador, 2018, p. 513).

En este contexto histórico particular:

El movimiento feminista que se expresó durante la transición fue un movimiento creativo y transgresor como pocos, que hizo que la sociedad y la vida de mujeres y hombres cambiara sustancialmente (aunque no todo a lo que aspirábamos). Sin considerarlo no nos podemos explicar de forma veraz lo que representaron esos años 70 e inicios de los 80, ni entender quiénes somos hoy y la sociedad en la que vivimos. Sin embargo, el protagonismo del feminismo, no aparece en el relato oficial de la transición (Montero y Cervera, 2018, p. 147).

Bengoechea (2006) nos previene acerca de cómo:

En la cultura española la aniquilación simbólica femenina se realiza a través de una serie de prácticas que se pueden resumir en su ausencia de discurso y en su consideración de ser subordinado inferior mediante: a) su adscripción por encima de todo al mundo 
doméstico, íntimo y familiar y b) su conversión en objeto visual erotizado en fragmentos como parte de su reificación (2006, p. 27)

En los años 70, la ciudad de Barcelona fue una sociedad "fecunda y un espacio mental alejado del poder político, desenfocado dentro de la España franquista" (Martí i Font, 2021) que gozó de un aparato editorial progresista que lanzó al mercado, ávido de novedades y modernidad, algunas revistas musicales como Tele Exprés, Popular-1, Star o Vibraciones.

Del Val (2011) recoge una cita de la biografía de Ribas (2007, p. 362) explicando que Barcelona, sede de la revista Vibraciones:

No vivió una única transición, sino que convivieron tres transiciones distintas: la social, organizada por los obreros emigrantes de Barcelona. La del cambio en las costumbres, que abanderaron los jóvenes de diferentes clases sociales, y la revolución política, que fue la menos revolucionaria $(2011$, p. 84$)$.

\subsection{LOS MEDIOS, GATEKEEPERS QUE FOMENTAN LA INVISIBILIDAD DE LAS MUJERES}

Gallagher (2015) alude a la agenda de los medios como la herramienta que acabará definiendo el grado de visibilidad y representación de la mujer y sugiere que este trato constituye una aniquilación simbólica: "the term, originally coined by George Gerbner in 1972 became a powerful and widely used metaphor to describe the ways in which media images make women visible" (2015, p. 23).

Cuando la mujer artista clama su autosuficiencia, se naturaliza la violencia mediática y el control de la palabra y del espacio público. El patriarcado, presente y vivo en los medios tradicionales, propició la infrarrepresentación y ocultación de la participación de las mujeres en la escena cultural y musical: "Gatekeepers are those who, very often, mediate not just between artists and audiences, but between artists and opportunity" (Hooper 2019, p. 137).

Raine y Strong (2019) señalan que la discriminación de género es estructural en las culturas de trabajo relacionadas con las industrias musicales, sector en que la mujer ha tenido que negociar las normas de género, enfrentándose a un techo de cristal y 
condenándola a la subordinación y ocultación de su producción cultural. Así lo expresa la vocalista, productora y compositora Maria José Peña del trio barcelonés Claustrofobia ${ }^{1}$, uno de los nuevos grupos surgidos en la escena pop-rock de principios de los 80: "Ellos se llevaban la fama, a mí los medios no me dieron voz ni la oportunidad de narrar mi propia versión de la historia".

Identificamos, por un lado, el relato androcéntrico de los medios de comunicación asumiendo los valores del patriarcado, y por otro, un sistema de validación que garantiza a los nuevos talentos la oportunidad de ingresar en el anhelado star sytem. Este proceso de inclusión y validación es ejecutado por los gatekeepers, quienes detentan numerosos niveles y roles de conexión con los/las artistas. Ambos mecanismos participan en la exclusión de la mujer en la industria musical derivando en una omisión de referentes femeninos en la historia de la música.

El crítico de rock, al que se refiere Maria José Peña de Claustrofobia, este gatekeeper que goza de los privilegios del patriarcado, es en muchos casos un profesional carente de capacitación musical o formación específicas apropiándose de una estética cercana a la rock star y detentando personalidades osadas y arrogantes. Pearson (2018) explica en Women of Rock Oral History Project cómo operan los mecanismos de infra representación.

Canons influence how we remember the past and rock journalism, media, and scholarship perpetuates a one-sided, androcentric rock narrative. Artists and music that fit easily into the existing masculinist "sex, drugs, rock ' $n$ ' roll" narrative are more likely to find a place in rock history, whereas those that do not are more likely forgotten or marginalized. Women do not easily fit, and so they continue to be underrepresented. If they are represented at all, they are not given the same level of attention or granted the same access to audience as their male counterparts.

\subsection{IDIOSINCRASIA DE LA REVISTA VIBRACIONES}

\footnotetext{
1 Entrevista telefónica efectuada el 21/5/2021
} 
Vibraciones aparece en los últimos meses de la dictadura franquista fundada por el periodista y comunicador catalán Ángel Casas, quien la dirige desde su inicio -en 1974- hasta 1977, aunque la revista dilató su andadura hasta 1982. Su ideario radicaba en establecer una revista moderna y apolítica: "en aquel momento el enemigo oficial, claro y sobre el que nadie tenía dudas era el franquismo, entonces vale todo" (Bronsoms, 2007, p. 39). La idea era iniciar una revista con impacto en el panorama musical. "Fue decidir que el mundillo, que la gente, que los músicos, que los críticos, estábamos lo suficientemente maduros para hacer una revista en serio, no de cotilleos o de fotos, sino una revista que abordara el tema en serio y a fondo" 2 .

El aperturismo social se reflejó en una juventud, de finales de los setenta y principios de los ochenta, que poseía conciencia como sujeto político. Su consolidación coincidirá con el contexto de recuperación de libertades en la España postfranquista, donde los medios de comunicación - especialmente la radio y la televisión - informaban sobre el rock español y las influencias de la música francesa e italiana.

En un entorno sociocultural y artístico en transformación, Vibraciones tomó la delantera a publicaciones musicales ya existentes: Fans, Mundo Joven, El Gran Musical, Disco Express, Popular-1. A principios de los años 1970, las publicaciones españolas tratan el fenómeno musical desde una óptica fan, subjetiva y sectaria dando preferencia a grupos de quienes los redactores eran aficionados: "Popular 1 tenía unas fotos increíbles, pero Vibraciones era más erudita" (Cervera, 2017).

Con el subtítulo: "Vibraciones habla de la evolución musical de los años 70", la revista se especializó en ofrecer contenidos eclécticos imitando publicaciones francesas como Rock et Folk, o las angloamericanas especializadas en rock ' $n$ ' roll tipo Rolling Stone o Village Voice. Una de sus fuentes era la idealizada New Musical Express, de quienes replicaban contenidos como la cultura de las drogas, el mundo oculto o los autores del nuevo periodismo, practicando un estilo con prevalencia de críticas sexistas centradas en la cosificación de la mujer y el cuestionamiento de sus habilidades.

\footnotetext{
2 Entrevista a Ángel Casas. Vibraciones, noviembre de 1978, número 50.
} 
La periodicidad de Vibraciones era mensual con unas 64 páginas compaginada a color que llegó a distribuir 15.000 ejemplares en 1980 mientras que Disco Express apenas consiguió 2000. Vibraciones evolucionó a la par que la actualidad musical mezclando entrevistas, artículos, la popular sección de los lectores, la información sobre conciertos o las reacciones polémicas sobre determinados artículos publicados.

Su envidiable distribución nacional fue el germen de una nueva cultura moderna en una sociedad donde el rock ya era consustancial a la juventud del país: "Era el bebedero obligatorio al que cualquier buen aficionado al rock, pero también al folk, el reggae y otros géneros, tenía que acudir (acudía) obligatoriamente" (Uribe, 2015).

Durante sus 8 cortos años de historia, la publicación fue la escuela de diversos redactores y entre las colaboradoras ocasionales, sólo encontramos dos mujeres, la reportera Patricia Godes y la fotógrafa Michele Curel. La única mujer que figura en el staff de Vibraciones compuesto por 10 hombres es Elisa Nuria Cabot, quién consta como directora de la publicación, pero en realidad era una figura legal, ya que en aquella época la dirección de una revista debía recaer en una persona que tuviera el título oficial de periodista. Así, la presencia de Cabot era el salvoconducto para que la redacción pudiera funcionar constatando que el espacio reservado a la mujer era en la base de la pirámide y no en la cúspide. Cabe recordar que en las décadas de los 70 y 80 del siglo XX, en la cultura empresarial de los medios, prevalecían condicionamientos de acceso a la esfera de lo público excluyendo a la mujer de roles ejecutivos, una estrategia de reservar los puestos de poder y estatus al hombre. "Masculine identities constantly have to be constructed, negotiated and reconstructed in routine social interaction, both in the workplace and elsewhere" (Collinson y Hearn, 1994, p. 8).

A finales del franquismo, los medios de difusión construyeron una realidad social de la mujer discriminatoria "escribiendo al dictado" del régimen hasta que, a finales de los años 1970, y en plena Transición, la profesión periodística tuvo más libertad de expresión. La participación de la mujer en la sociedad a finales de los años 70 va adquiriendo carta de naturaleza. En cualquier caso, su vocabulario "y maneras de entender la realidad estaban tamizadas por el punto de vista tradicional, masculino, 
excluyente y desigual que venía elaborando estereotipos y contenidos trivializados sobre las mujeres" (López Díez, 2000, p. 42).

Con el objeto de ejemplificar las prácticas excluyentes nos centraremos en el análisis de Vibraciones, una publicación donde se combinan los elementos de modernidad en los contenidos, con los tratamientos periodísticos misóginos y estereotipados acordes con las mentalidades de 1980.

Los estereotipos nacen como respuesta a una amenaza contra el grupo social dominante y su función es la de justificar la conducta del grupo que cree en ellos. Se trata de un poderoso instrumento de información que permite catalogar el mundo real desde lo subjetivo, y sirve para proteger los intereses del grupo dominante, en el caso de la investigación que nos ocupa, el llamado patriarcado del rock.

Los estereotipos son un sistema de categorización que describen a un grupo, por tanto, cualquier estereotipo es predominantemente evaluativo. Dando como válido este concepto, podemos afirmar que al examinar categorías sociales como "la mujer en el rock" distorsionaremos la visión según seleccionemos unos atributos en detrimento de otros.

El staff de la revista, al aceptar los estereotipos de manera natural, les da status de credibilidad, ya que parecen naturales y obvios porque casi todo el mundo comparte el conocimiento de su existencia. Pero la selección se basa en una serie de prejuicios sobre el grupo. "La veracidad del estereotipo yace en la selección de las características" (Quin, 1996, pp. 227-228). En el siguiente apartado analizamos como los estereotipos impregnan el ADN de la revista.

\section{METOdOLOGÍA}

\subsection{OBJETIVOS, HIPÓTESIS Y PREGUNTAS DE INVESTIGACIÓN}

Esta investigación quiere ofrecer un análisis de la revista Vibraciones para poder comprender la naturaleza del fenómeno discriminatorio ejercido contra las mujeres artistas en la prensa musical en España y, en concreto, en una revista emblemática de la década de los 80 del siglo XX. El objetivo de la presente investigación es demostrar la 
invisibilidad de las aportaciones de las mujeres en la prensa musical española y comprender los mecanismos que intervienen en esta práctica de ocultación y tratamiento discriminatorio.

H1. Existe una escasa representación de género en la prensa musical.

P1. ¿Hasta qué punto se refleja la falta de representación de género en la revista Vibraciones?

P2. ¿Actuó la revista Vibraciones como gatekeeper al discriminar a las mujeres?

H2. El trato que sufren las mujeres en la prensa musical es discriminatorio y reside en el manejo de estereotipos sexistas en los contenidos.

P1. ¿Adoptó la prensa musical un sesgo de género hacia la creatividad de las mujeres?

P2. ¿Con qué herramientas específicas se establecieron los estereotipos y la exclusión?

\subsection{METODOLOGÍA UTILIZADA}

La metodología escogida para responder a nuestras preguntas de investigación es el análisis de contenido ya que ha demostrado ser un método útil para la observación de la representación de género en los medios, y uno de los más empleados cuando queremos realizar una aproximación al objeto de estudio desde un enfoque cuantitativo y cuantitativo (Capecchi, 2014).

Es asimismo una herramienta idónea para determinar aspectos cuantitativos sobre la presencia y ausencia de las mujeres artistas en las publicaciones y revelar los patrones en el tratamiento de los textos informativos (Franquet, Luzón, y Ramajo, 2011).

El procedimiento de la observación ha consistido, en primer lugar, en un vaciado de todos los ejemplares de Vibraciones del año 1980 para determinar el protagonismo que adquirían las mujeres en los textos, imágenes y las distintas portadas con la observación de las fotografías y los titulares. El estudio ha dejado fuera las secciones ajenas a la 
información musical como: críticas de cine o literatura, cartas al director, cotilleos, anuncios publicitarios o agenda de conciertos. Finalmente se ha utilizado el análisis crítico del discurso para descubrir los tratamientos sexistas particulares que mostrasen los diferentes modelos de estereotipos.

El análisis cualitativo de los estereotipos de género se complementó, siempre que fue posible, con las aportaciones de fuentes como entrevistas, webs, publicaciones alternativas, periódicos, expertos/as del sector que permitiesen clarificar aspectos específicos del análisis y contextualizar los hallazgos.

\section{RESULTADOS}

Con el propósito de obtener respuestas y dirigir una mirada crítica sobre cómo los medios de comunicación musicales ejercieron la discriminación de género ocultando la representación creativa de las artistas en el rock ' $n$ ' roll, presentamos los resultados derivados del estudio sobre la prensa musical efectuado sobre la revista Vibraciones.

En primer lugar, la metodología elegida para categorizar la presencia-ausencia de las mujeres fue analizar los contenidos de la revista durante todo el año 1980, cuando se había consolidado en el mercado y contaba con un número significativo de seguidores/as y con una tirada de 15.000 ejemplares mensuales. Esta opción permitió ver la evolución de los contenidos en un período clave de la revista.

El objetivo del análisis era establecer las diferencias de presencialidad y protagonismo de las mujeres dedicadas a la música y preguntamos sobre cómo se ejercía la discriminación en el tratamiento informativo de la mujer en el rock. En este caso para profundizar en ese procedimiento necesitábamos un análisis cuantitativo y cualitativo, con perspectiva de género, que permitiese demostrar la hipótesis de partida sobre como una visión misógina de la mujer en la sociedad patriarcal invisibilizó las aportaciones de las artistas en la música rock fundamentándose en la transmisión de estereotipos discriminatorios.

En la fase analítica se catalogaron y midieron todas las informaciones, especificando los contenidos e imágenes protagonizados por mujeres, así como los estereotipos que dichos contenidos transmitían. Se estableció un baremo de palabras por página tomando como 
referencia un muestreo de tres páginas diferentes de la publicación. Con esta codificación el estudio cuantificó líneas de texto, y palabras referidas a mujeres, así como fotografías, confirmando que, de las casi 800 páginas de los 12 ejemplares de Vibraciones publicados en 1980 , sólo un $9,7 \%$ de sus contenidos estaban protagonizados por mujeres.

Tabla 1. Presencia mujeres en palabras de texto en Vibraciones 1980

\begin{tabular}{|c|c|c|c|}
\hline Editora & $\begin{array}{c}\text { Palabras totales } \\
\text { publicación }\end{array}$ & $\begin{array}{c}\text { Palabras sobre } \\
\text { mujeres }\end{array}$ & \% total \\
\hline Vibraciones & 360.074 & 34.870 & $9,7 \%$ \\
\hline
\end{tabular}

Fuente: Elaboración propia

En el proceso analítico de las imágenes se cuantificaron 693 de las que sólo 84 pertenecían a mujeres, concluyendo que su visibilidad no superaba el $12 \%$. En consecuencia, casi el $90 \%$ de las imágenes correspondían a varones, lo que verifica una de nuestras hipótesis de partida.

Tabla 2. Presencia mujeres en número de fotografías en Vibraciones 1980

\begin{tabular}{|c|c|c|c|}
\hline Editora & Fotos total & Fotos mujer & \% total \\
\hline Vibraciones & 693 & 84 & $12 \%$ \\
\hline
\end{tabular}

Fuente: Elaboración propia

Una vez establecida su escasa representación, se establecieron las variables para categorizar los estereotipos relacionados con atributos físicos, vida privada y pública, de mujer objeto o mujer vicaria. El cómputo final, después del vaciado, otorgó que un 71\% de sus contenidos eran compatibles con la cosificación de la mujer, demostrando que el lenguaje de los medios se utiliza como un arma de control ejecutando opresión, y en el caso de Vibraciones, impregnando la obra de las mujeres de una misoginia que trasciende fronteras culturales, geográficas y estéticas

Tabla 3. Estereotipos en textos en Vibraciones 1980

\begin{tabular}{|c|c|}
\hline Estereotipo texto & Vibraciones \\
\hline Atributo físico & $71 \%$ \\
\hline Vida privada & $12 \%$ \\
\hline Vida pública & $5 \%$ \\
\hline Mujer objeto & $9 \%$ \\
\hline Mujer vicaria & $3 \%$ \\
\hline
\end{tabular}

Fuente: Elaboración propia 
En las tres portadas con protagonismo femenino, de las 12 publicadas en 1980, destacamos la que protagoniza Debbie Harry (Ilustración 1), cantante, compositora, modelo y actriz norteamericana del grupo mixto Blondie, con un titular que es eufemismo que tiende a reforzar la ideología de género: "bueniiiiisima Blondie".

Ilustración 1. Portada 1 (Blondie), Portada 2 (Marilyn Monroe), Portada 3 (Cindy Wilson)
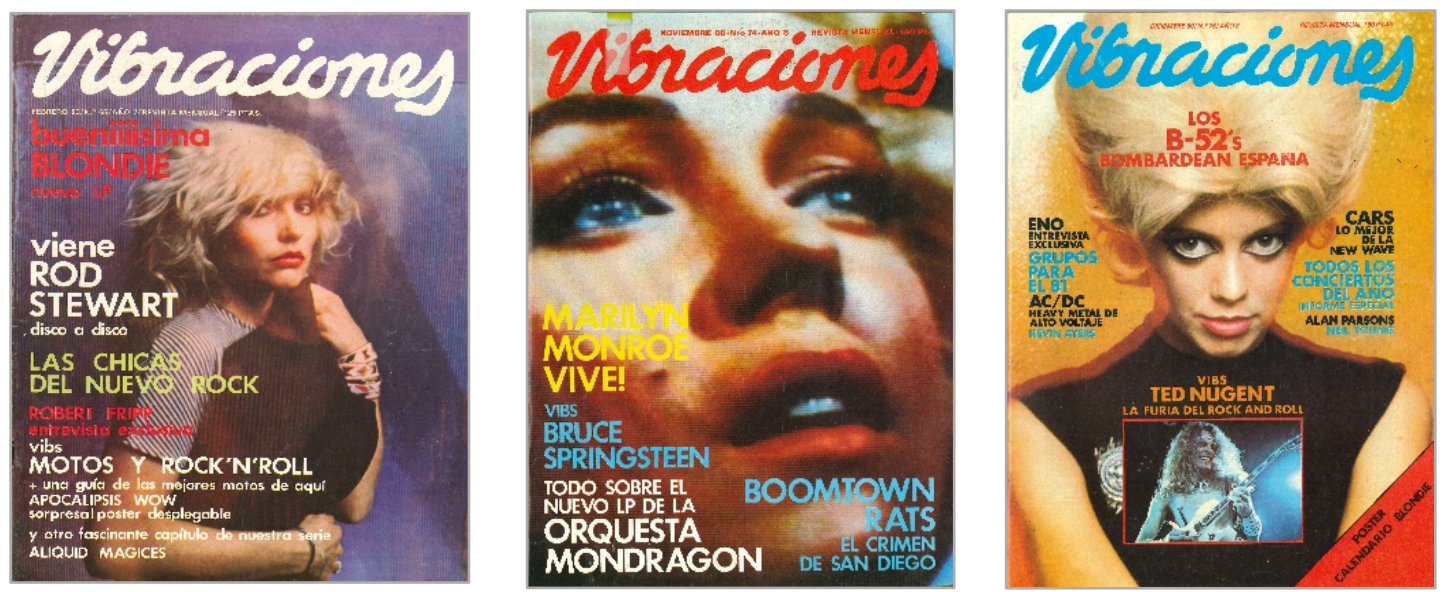

Fuente: Revista Vibraciones 1980. Ejemplares 65 (enero), 74 (noviembre) y 75 (diciembre)

En la misma portada destaca el titular: "Las chicas del nuevo rock" un genérico femenino que engloba a todas las mujeres desestimando cualquier acción individual que hayan protagonizado y desdibujando el objeto de interés. En el análisis de la construcción del discurso, Bengoechea (2015) sugiere que tengamos presente la teoría de la valoración:

Para hacer visibles las presuposiciones sexistas o androcéntrica que gobiernan o laten en un texto (cuando existen), preguntándose a quién va dirigido, a quién habla, quién es el sujeto implícito, así como las condiciones de recepción: cómo se recibe ese mensaje implícito, dónde se sitúa a mujeres y hombres y qué consecuencias tiene en sus vidas este tipo de mensajes (2015, p. 115).

La portada de Debbie Harry enfatiza la salida del nuevo disco del grupo que es objeto de crítica en la página 44 del ejemplar de enero 1980. El reportero le confiere la forma de una carta escrita por la mano de un fan, en la que, con un estilo irreverente y un lenguaje acosador, confiesa intimidades de forma posesiva a "Debbie". "En Vibraciones ERES MIA, y cuando alguien escribe una nota sobre ti me pongo celoso, es como si coquetearas con otro rock-kritik".

RAE-IC, Revista de la Asociación Española de Investigación de la Comunicación vol. 8, núm. 16 (2021), 72-97 
La omisión del apellido de Deborah Harry ya es un intento de familiarizarnos con la protagonista presentándola estereotípicamente como una mujer objeto. En su reciente autobiografía, Harry, ha relatado que con su agencia palió la cosificación y misoginia con la que la atosigó la industria musical (Harry, 2019).

Johnson-Grau (2002), enjuicia que si el crítico evalúa el atractivo físico desvía su atención de su capacidad artística: "The sexual meaning of rock ' $n$ ' roll becomes defined by the sexual preferences of the rock critic" (2002, p. 213). Bengoechea (2015) sugiere que, en el análisis de la organización de las frases, y más allá de la transitividad, se examine la agencia, la nominalización y la concesión de voz en los discursos.

En el presente análisis mediado por la estilística femenina, apreciamos una exhibición del hombre como hablante, y a la mujer como un fin, como un objeto: "yo deseo, si me permites, un tête-a-tête contigo". De nuevo, vemos reproducidos unos clichés de género totalmente anacrónicos, una frivolidad que seguramente queda justificada en una publicación de rock pero que son una rémora para la igualdad (Gallego, 2013).

La portada número 2 (Ilustración 1) es una fotografía fragmentada de una mujer a la que identificamos por el titular: “Marilyn Monroe vive!”. Damián García Puig, su editor, justifica la elección de esta portada de esta forma: "Buscábamos algo distinto, no la foto de la Monroe mil veces vista y ahora vuelta a publicar. Algo insólito. Y Francesc Fábregas situó su cámara delante de la TV en color, consiguiendo por fin la impresionante instantánea que ocupó la portada: una Marilyn desconocida y conmovedora, la Marilyn agonizante de "Niágara" ${ }^{3}$. La mirada cándida y perdida de Marilyn Monroe, su boca entreabierta y suplicante, implorando ayuda, es una cara que refleja sufrimiento, agonía -como sugiere el editor-. Es un claro efecto de la manipulación y de la invisibilidad de las mujeres artistas.

La tercera portada (Ilustración 1), la protagoniza la cantante y compositora Cindy Wilson, componente del cuarteto mixto norteamericano B-52, cuya representación es, de nuevo, la de una mujer pasiva. La elección de esta portada, según esclarece el editor

\footnotetext{
${ }^{3}$ Vibraciones. Ejemplar 75. Diciembre 1980
} 
en la página 5 del ejemplar de diciembre de 1980, fue fortuita ya que el interés principal de la publicación era identificarse con "un toque furiosamente roquero..." "Al principio queríamos poner a Ted Nugent, más que nada para volver a dar a Vibraciones el toque furiosamente roquero, heavy, que desde la cubierta con Police había perdido. Pero sucedió que la única foto que nos convenía de Nugent era apaisada..."4.

La elección de las portadas en Vibraciones no se vincula a una política editorial, sino que tomaba en consideración criterios de diseño o editoriales. Es el caso de la portada 3 en la que ni tan siquiera se entrevista a Cindy Wilson, o a su grupo; la verdadera misión de sus editores era reservar la portada privilegiada a "Ted Nugent, la furia del rock and roll". "Rock is lived by its male (or honorary male) audience, to the exclusion of girls and women" (Reddington, 2012, p. 167).

A continuación, y a modo de ejercicio comparativo, presentamos ejemplos de textos en los que identificamos una serie de categorizaciones en las que sus protagonistas comparten un imaginario, cuyo denominador común es la denostación de su aspecto morfológico y físico (Ejemplar 68, mayo 1980, p. 18):

- Neumáticas: “LA NEUMÁTICA DOLLY PARTON hace de secretario (¿uh?) de Jane Fonda en una próxima película..."

- Guerrilleras: "LAS SLITS, GUERRILLERAS del nuevo rock continúan en la brecha...",

- Doradas: "Otro cambio ambiental. Es el de Linda Rondstadt. Después de saltar hacia un sonido "nuevaolero" en su último plástico, la chica dorada del rock blando californiano se lo monta de actriz teatral..." (Ejemplar 68, mayo 1980, p. 15)

Entendemos que el epíteto guerrilleras" se atribuye a que la portada de su disco Cut consistió en una declaración de intenciones mostrando una imagen insurrecta que incumplía los mandatos de género (Ilustración 2).

\footnotetext{
${ }^{4}$ Vibraciones. Ejemplar 75. Diciembre 1980
} 
lustración 2. Dolly Parton (1980), The Slits (1980)
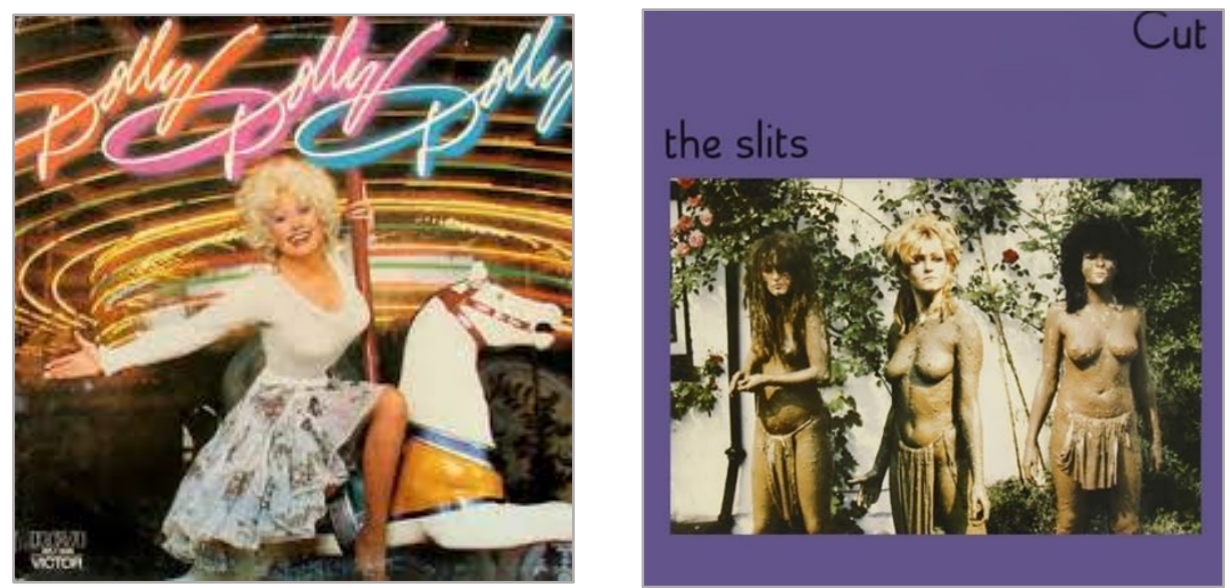

Fuente: Recuperado de Internet

Los dos ejemplos siguientes reproducen estereotipos de género clásicos.

- Vicaria: “La MARIANNE FAITHFUL (que fue consolada por Anita Pallenberg, otra ex chica Stone)"

- Cosificada: LA BELLA TANYA TUCKER rehúsa una oferta de muchos ceros para posar en "Playboy".

Los titulares protagonizados por hombres y mujeres ponen de manifiesto que las representaciones de género en Vibraciones son asimétricas. En las informaciones relativas a grupos masculinos, el hombre es personificado como sujeto, y nombrado con sus apellidos y con epítetos que le relacionan con acciones de poder - de irreverencia e incluso salvajismo-, un concepto en consonancia con la idea de que a ellos sí se les permite saltarse las normas. En los ejemplos se reivindica una masculinidad superior canonizando y legitimando un discurso plagado de adjetivos y metáforas de dudosa credibilidad dirigidos a lectores heterosexuales blancos de una edad determinada.

- John Cale, el hombre maldito de Velvet Underground

- Roger Daltrey enemigo público no1

- Michael Jackson. Bio: ritmos de negro platino

- The Police, triunfar sin poner el culo

- La venganza de los Sex Pistols

RAE-IC, Revista de la Asociación Española de Investigación de la Comunicación vol. 8, núm. 16 (2021), 72-97 
- Ted Nugent, la furia del rock and roll

- Status Quo, un repaso entre piernas. Quorum por pelotas

- El paquete de Marlon Brando

- El despertar del Poseidón

- Police, la fórmula de la energía

En los titulares sobre mujeres, en cambio, se usan eufemismos peyorativos que sexualizan o infantilizan a la mujer naturalizando una visión androcéntrica que confluye con la sexista y en la aniquilación simbólica femenina apelando al subconsciente colectivo con expresiones generalistas como:

- Joni Mitchel entre las sábanas

- Las chicas de Madrid

- Las chicas del nuevo rock

- El cuerpo del delito

- La gran dama de occidente

- Hacérselo en las calles

- La bruja americana

- La ciudad de las mujeres

- La rosa judía

- Otra chica nueva

La discriminación por razón de sexo/género que han ejercido los medios de comunicación es una violencia simbólica que contienen una visión instrumental de las mismas con múltiples consecuencias en su vida cotidiana (Verdú Delgado, 2018). A continuación, ofrecemos un ejemplo de estas prácticas discriminatorias que perpetúan una imagen sesgada de los logros conseguidos por las artistas. 
La ilustración 3 es un reclamo publicitario carente de autoría que remite a una representación fragmentada y cosificada de la mujer ilustrándonos en una mejor comprensión de la ideología de la publicación estudiada. En ella se reproducen los cuerpos de doce mujeres desnudas arrastrándose en actitud desolada mientras un hombre de pie, vestido $-\mathrm{y}$ ajeno a su dolor-, sostiene un micrófono en una mano, $y$ en la otra un ejemplar de Vibraciones del mes en curso. Dado que está fechada en 1980, en el contexto político y social de la postdictadura franquista, podemos argumentar que fue un momento en el que la sociedad aspiraba a escribir una nueva identidad nacional, moderna, y romper con el puritanismo.

"La lúdica expresión y exuberante sexualidad de aquellos años se ha explicado a menudo como la necesidad de liberar una libido social que en general podemos asumir que se encontraba reprimida o restringida" (Vilarós, 2018, p. 253). La libido latente de la redacción de Vibraciones enmascara su machismo con una representación actualizada de la iconografía cultural de dominación del patriarcado, el sistema que oprime y explota a la mujer.

Ilustración 3. Ejemplo de la ideología de la publicación

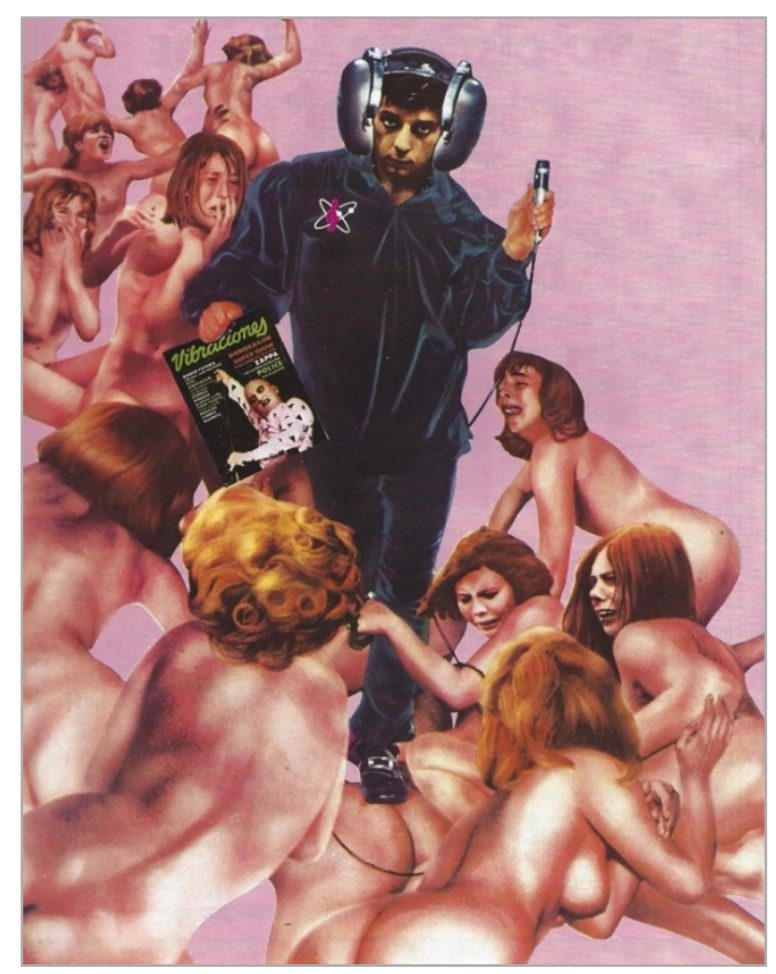

Fuente: Vibraciones № 67, abril de 1980 (página 4) 
Otorgamos que la imagen que difunde de la mujer es un voyerismo controlado por una mirada alejada, transmitiendo otredad. El cuerpo femenino aparece despedazado, fragmentado y parcelado contrastando con el del hombre que actúa completo. Parafraseando a Simone de Beauvoir: "Men, in defining themselves as "the One", position women as "the Other" (Pilcher and Whelehan, 2017, p. 96). Es la expresión sexista que refleja la subordinación de la feminidad mientras la masculinidad se define como superior.

Bengoechea (2006) considera que el tratamiento que reciben las mujeres por parte de los medios como grupo inferior, subordinado, denigrado, recibe el nombre de aniquilación simbólica - término que acuño Gaye Tuchman en 1978- y es un rasgo presente en la mayoría de las prácticas hegemónicas en el discurso público. En esta ilustración, la mirada de desprecio roza la degradación mediante una cosificación y una misógina en su trato hacia la mujer.

\section{CONCLUSIONES}

En la década de los setenta y ochenta, las ideas generadas por el movimiento feminista influenciaron a las mujeres que querían dedicarse a la música facilitándoles los referentes ideológicos y mentales para desafiar la autoridad patriarcal y escoger el camino de la provocación como estrategia creativa y actitud rompedora para mostrar al mundo su talento. Así como, muy ocasionalmente, en otras revistas musicales coetáneas internacionales se manifiesta una actitud rompedora y comprometida con el feminismo emergente, esta complicidad no aflora en el caso de la revista Vibraciones.

El análisis cuantitativo arroja luz sobre la primera hipótesis relativa a la representación de género en la prensa musical. En Vibraciones se han cuantificado 360. 074 palabras en los 12 ejemplares de 1980, de las cuales 34.8970 aluden a mujeres y representan el 9,7\%. Respecto a las fotografías, su presencia se reduce a 84 de 693 imágenes publicadas y equivalen a un $12 \%$.

La segunda hipótesis, referida al sesgo de género hacia la creatividad de las mujeres se ha demostrado mediante el análisis de contenido cualitativo revelando que se ejecutó 
con el manejo de estereotipos sexistas. Únicamente tres, de las doce portadas de 1980, están protagonizadas por mujeres, y mientras en ellas al hombre se le personifica con nombre propio y epítetos que infieren poder, un valor de prestigio en la cultura del rock: "The Police, triunfar sin poner el culo", "Ted Nugent, la furia del rock and roll", "Status Quo, un repaso entre piernas", "Quorum por pelotas", la mujer es aniquilada simbólicamente. Titulares como: “Joni Mitchel entre las sábanas”, "La bruja americana”, "La rosa judía" indican que, además de obsoletos, el prejuicio sexual ha incidido en la forma en que se edita Vibraciones y tiene como consecuencia no otorgar a las artistas el prestigio transgresor que se atribuye a los músicos.

El discurso del periodista musical es restrictivo para unos, y condescendiente con los otros, un empirismo que queda reflejado en el análisis de contenido cualitativo donde hemos tomado como referencia conceptual los siguientes términos: androcentrismo, otredad, sexismo y cosificación. La invisibilidad y el tratamiento sesgado eran la lógica dominante en la redacción de Vibraciones que quería reconocimiento en la industria musical y entre el público masculino.

El androcentrismo describe la práctica de asumir las experiencias de los hombres como la norma y las de las mujeres como una desviación de esta norma por una especificidad de su sexo. Dicha percepción de la realidad, desde la mirada masculina, segmenta a mujeres y hombres, reforzando estereotipos, y transmitiéndola a toda la producción cultural. Unas prácticas periodísticas que conllevan la invisibilidad de las mujeres y la ocultación de sus aportaciones, como ocurre en el caso que nos ocupa.

La cosificación como teoría, sugiere que los medios, con su función socializadora, cosifican el cuerpo de la mujer y lo hacen sexualizando en la forma que presentan los cuerpos y enfatizan su presencia. Es una forma de violencia machista difícil de identificar porque la hemos normalizado. El estudio de las formas de desigualdad del pasado, y las sanciones de género corporeizadas mediante los estereotipos, nos han permitido localizar las grietas de este espacio hostil que es el rock y discernir el imaginario en la sociedad actual. Analizar el pasado para interpretar mejor el presente es donde radica el valor de nuestra investigación. 


\section{REFERENCIAS BIBLIOGRÁFICAS}

Alonso, M. y Furio, E. (2007). El papel de la mujer en la sociedad española. Recuperado de https://cutt.ly/ZE53k3T

Bengoechea, M. (2006). Rompo tus miembros uno a uno (Pablo Neruda). De la reificación a la destrucción en la iconografía literaria de la amada. Cuadernos de Trabajo social, 19, 25-41.

Bengoechea, M. (2015). Lengua y género. Madrid: Editorial Síntesis S.A

Bronsoms, A. (2007). Animals de rock and roll. Barcelona: Pórtic.

Butler, J. (1990). Gender trouble. New York: Routledge.

Butler, J. (2002). Cuerpos que importan. Sobre los límites materiales y discursivos del sexo. México: Paidós.

Byerly, C.M. y Ross, R. (2006). Women \& media. A critical introduction. UK: Blackwell Publishing.

Capecchi, S. (2014). Methodological Problems in Gender and Media Research. Qual Quant, 48, 837-844. https://doi.org/10.1007/s11135-012-9805-1

Cervera, R. (2 de abril de 2017). Los recuerdos no pueden esperar. Revistas de música que vienen del pasado. Valencia Plaza. Recuperado de:

https://valenciaplaza.com/revistas-de-musica-que-vienen-del-pasado

Collinson, D. L. y Hearn, J. (1994). Naming men as men: implications for work, organization and management. Gender, Work and Organisation, 1(1), 2-22.

Cusick, S. J (1994). Feminist Theory, Music Theory, and the Mind/Body Problem. Perspectives of New Music, 32(1), 8-27.

Del Val, F (2011). Pasotismo, cultura underground y música pop. Culturas juveniles en la transición española. Revista de Estudios de Juventud, 95, 74-91. 
Feixa, C. y Porzio, L. (2004). El tema. De las tribus urbanas a las culturas Juveniles. Revista de estudios de juventud, 61(3), 1-3.

Martí i Font, J. M. (22 de mayo de 2021). La Barcelona de la contracultura. La Vanguardia. Recuperado de https://cutt.ly/5E53hFm

Franquet, R., Luzón, V. y Ramajo, N. (2007). La información en los principales medios de comunicación on-line. Estudiar la representación de género. Zer-Revista de estudios de comunicación, 12(22), 267-282.

Gallagher, M. (1981). Unequal opportunities. The case of women and the media. Unesco representation of women.

Gallagher, M. (2015). The media and the representation of gender. En C. Carter, L.Steiner y L. McLaughlin (Eds.), The Routledge companion to Media and Gender (pp 23-31). New York: Routledge.

Gallego, J. (2013). De reinas a ciudadanas: Medios de comunicación, ¿Motor o remora para la igualdad? España: Aresta Mujeres.

Gil Calvo, E. y Menéndez, E. (1986). Ocio y prácticas culturales de los jóvenes. Madrid: Instituto de la Juventud.

Harding, S. (1987). Is there a feminist Method? En S. Harding (Eds), Feminism and Methodology (pp. 9-34). Bloomington, Indianapolis: Indiana University Press.

Harry, D. (2019). Face it. New York: HarperCollins Publisher.

Hooper, E. (2019). The Gatekeeper gap: searching solutions to the UK's ongoing gender imbalance in music creation. En S. Raine y C. Strong (Eds.), Towards gender equality in the music industry (pp. 131-146). New York: Bloomsbury Academic.

Johnson-Grau, B. (2002). Pop music and the press. En S. Jones (Ed.), Sweet nothings: Presentation of women musicians in pop journalism (pp. 202-218). Philadelphia: Temple University Press.

Keane, J. (2004). Violence and democracy. Cambridge: Cambridge University Press. 
Labrador, G. (2018). La transición como revolución cultural: democracia por venir y formas de vida civiles frente a los partidos e instituciones del estado. E En D. Corbeira y H. Coria (Eds.), Las otras protagonistas de la Transición. Izquierda radical y movilizaciones sociales (pp. 513-520). FSS ediciones: Madrid.

Lagarde, M. (1996). La perspectiva de género. En Género y feminismo. Desarrollo humano y democracia. (pp. 13-38). España: horas y HORAS.

Lauretis, T. (1989). Technologies of gender. Essays on Theory, film, and fiction. London: Macmillan Press.

López Díez, P. (2000). La construcción mediática de género en los libros de estilo. En M. T. López de la Vieja (Ed.), Feminismo: Del pasado al presente (pp. 35-48). España: Ediciones Universidad de Salamanca.

Mills, S. (1995). Feminist Stylistics. London: Routledge.

Montero, J. y Cervera, M. (2018). Feminismo insumiso en la Transición. En D. Corbeira y H. Coria (Eds.), Las otras protagonistas de la Transición. Izquierda radical y movilizaciones sociales (pp.147-154). FSS ediciones: Madrid

Montoro, R. (2014). Feminist Stylistics. En M. Burke (Ed.), The Routledge Handbook of Stylistics (pp. 346-361). New York: Routledge.

McClary, S. (1994). Same as it ever was: youth culture and music. En E. McDonnell y A. Powers (Eds.), Rock she wrote (pp. 440-454). London: Plexus.

Navarro Beltrá, M. y Martín Laguno, M. (2011). El sexismo publicitario: delimitación de conceptos e indicadores de género. Estudio empírico de la producción científica. Pensar la Publicidad. Revista Internacional de Investigaciones Publicitarias, 5(1), 51-73. https://doi.org/10.5209/rev_PEPU.2011.v5.n1.36922

Lomas Martínez, S. (2018). Travestismo, homosexualidad y autoría queer durante el Franquismo. Más bonita que ninguna (1965). Zer, 23(44), 19-23.

https://doi.org/10.1387/zer.17945 
Quin, R. (1996). Enfoques sobre el estudio de los medios de comunicación: la enseñanza de los temas de representación de estereotipos. En R. Aparici, La revolución de los medios audiovisuales (pp. 225-232) Madrid: Ediciones de la Torre.

Pearson, T. (2018). Women of rock oral history project. Recuperado de http://www.womenofrock.org

Pilcher, J. y Whelehan, I. (2017). Key concepts in gender studies. London: Sage Publications.

Raine, S. y Strong, C. (2019). Towards gender equality in the music industry. Education, practice, and strategies for change. New York: Bloomsbury academic.

Reddington, H. (2012). The lost women of rock. Sheffield, UK: Equinox Publishing Ltd. Ribas, J. (2007). Los 70 a destajo. Ajoblanco y libertad. Barcelona: RBA.

Rubio Gil, A. y San Martín, M. A. (2012). Subculturas juveniles: identidad, idolatrías y nuevas tendencias. Revista de Estudios de Juventud, 96, 197-213.

Uribe, M (17 de enero de 2015). Vibraciones, la revista rock de los 70, el orgullo de Ángel Casas (Entrada blog). Recuperado de https://cutt.ly/yE580jR

Verdú Delgado, A. D. (2018). El sufrimiento de la mujer objeto. Consecuencias de la cosificación sexual de las mujeres en los medios de comunicación. Feminismo/s, 31, 167-186. Recuperado de http://rua.ua.es/dspace/handle/10045/7668

Vilarós, M. T. (2018). El mono del desencanto. Una crítica cultural de la Transición Española (1973-1993) Madrid: Siglo XXI de España Editores. 